\title{
Querying Inter-disciplinary Approaches
}

\author{
Daniel Goldberg
}

Published online: 1 November 2013

(C) Springer Science+Business Media New York 2013

The medical and health humanities are, if nothing else, interdisciplinary. Interdisciplinary work is an academic colossal squid: a creature much spoken of, but rarely seen. There are multiple reasons for this. First, the political economy of higher education in the US at least is not set up to encourage interdisciplinary studies. ${ }^{1}$ True, deans and administrators often wax poetic on the merits of interdisciplinary work, but deans and administrators generally do not hire faculty. Departments hire faculty. And the sociological fact is that people tend to hire others who resemble them. Where most departments are instituted along disciplinary lines, one would expect that most faculty training and expertise hew to such lines.

Second, interdisciplinary work is extraordinarily difficult. It is not simply multidisciplinary. Multidisciplinary work is itself a treasure inasmuch as it brings scholars and/or practitioners with varying skills and expertise into collaboration. To borrow an example from my own fields, public health law research as a nascent inquiry took off especially when trained social scientists began working in teams with experienced legal scholars. But as laudable and significant as high-quality multidisciplinary work is, it is not equivalent to interdisciplinary work. The critical distinction lies in the fact that multidisciplinary work generally is not integrative. What does this mean? Integration means that insights, perspectives, and approaches from different disciplines are synthesized into a cohesive whole that is not reducible to the sum of its parts. ${ }^{2}$ For example, Wood's analysis of disability and gender in Japanese sports manga and McDaniel's work on disability in Phenomena both draw from critical theory, film studies, and of course, disability studies (itself a field that lends itself to interdisciplinary work). But neither paper is equivalent to any of these

\footnotetext{
${ }^{1}$ See, e.g., Augsburg and Henry (2009) and Frodeman et al. (2010).

${ }^{2}$ See Repko (2012).

D. Goldberg (ه)

Greenville, NC, USA

e-mail: goldbergd@ecu.edu
} 
approaches in their own rights. (This is not a criticism, nor does it imply that somehow interdisciplinary work is superior to multidisciplinary or unidisciplinary studies. The utility of each of these approaches will depend almost entirely on the subject under consideration and the goals of the inquiry.)

Applied in academic contexts, interdisciplinary studies are no less fundamentally a form of scholarship than its brethren. While this idea in the abstract is unlikely to be controversial, applied to the medical and health humanities, it becomes much more elusive. One of the most urgent questions for medical and health humanities scholars is whether the primary objective of their efforts is to facilitate more humane and caring health providers. I reject this view completely, although not because such a goal is unimportant. If engagement with great books, dramas, and scholarship from the studia humanitatis enhances the moral imagination and contributes to what Rita Charon terms "narrative medicine," 3 that is all to the good. Rian and Hammer's essay picks up on this point, and actually starts from the premise that narrative medicine is a means to better patient care. Similarly, if, as per Lewis's essay, thinking through the antiheroic aspects of Walter White in Breaking Bad helps providers better understand their cancer patients, who could object to that? The problem with casting the objective of the medical and health humanities as engaged primarily in the production of more virtuous health providers is that it reduces the endeavor to a purely instrumental affair. The problem with reductionism is not that it is false-the problem with reductionism is rather that it is reductionist. The worth of the medical and health humanities becomes a function of the extent to which it creates virtue, which is problematic in its own right because how, exactly, could an adherent demonstrate that such actually occurs? Aristotle's entire theory of ethics is devoted to exploring the question of whether arête can in fact be taught at all-showing such is an extraordinarily difficult task by almost any standard.

Ironically, lashing the medical and health humanities to the oxcart of health care provision compounds the problem, for claims of efficacy then become more likely to be scrutinized by the standards and expectations that prevail in the health sciences and institutions of higher learning devoted to such. Suffice it to say that showing via scientifically acceptable methods how instruction in the medical and health humanities leads to more humane and empathic clinical practice is going to be... difficult. Rian and Hammer's emphasis on the ways in which narrative medicine may act as a scaffold for improved and empathic health care services is inspiring and useful even though the particular forms of rhetoric used may or may not be persuasive to an audience accustomed to seeing entirely different categories of evidence and arguments. This is an example of what makes a field like this one an amorphous as it is important-but that means engaging with its breadth.

The notion that the medical and health humanities exist "only" to improve health (care) encounters (not the argument of the papers here, but one that is certainly cogent) is also wrong on its own terms. The medical and health humanities in academic context are forms of scholarship. Done well, they require significant training, rigorous methods, and-notwithstanding the many limitations of peer review - the acceptance of methods and findings by trained and expert colleagues.

\footnotetext{
${ }^{3}$ Charon (2001)
} 
The medical and health humanities produce knowledge that is in an important sense no different from the categories of knowledge produced via any other scholarly endeavor. Insofar as such production is intrinsically valuable, the medical and health humanities are so valuable, regardless of whether their practice produces an iota of increase in the virtue of health providers.

The instrumentalism that so often accompanies the medical and health humanities is especially disturbing to many historians of medicine, in part because the value of understanding the past must not and cannot be reduced to the extent to which it improves understanding about the present. That it often does is independently important; there is widespread agreement that the history of public health is of great worth in instructing contemporary stakeholders on just public health practice and policy. ${ }^{4}$ Similarly, there is no question that Schillace's essay on brain trauma, moral insanity, and ideas of self-control in Victorian fiction and science suggests a number of significant implications for thinking through contemporary issues of neuromania, moral and legal culpability, stigma, and mental illness (and to this I can speak with some confidence given that Schillace's paper is the entry in the special issue on which I can claim of the most expertise). But the usefulness of history does not justify the reductionism inherent in the instrumentalization of the medical and health humanities. The past, David Lowenthal famously observed, is a foreign country, ${ }^{5}$ and it is insulting, not to mention vaguely imperialistic and colonial, to suggest that we ought to study other cultures primarily because doing so helps us "learn about ourselves." That such study often does do so, and that such is indeed a good thing, does not erase the potential narcissism in asserting that the primary value of attempting to increase understanding about other forms of life is simply as a means of understanding our own culture and society. To that end, the great value of MacLehose's impressive study of sleepwalking in medieval culture and its relationship to conceptions of body and soul is surely not that it helps contemporary sleep medicine physicians ply their craft with more virtue. Accordingly, historian of medicine Roger Cooter rightly objects to a vision of scholarship in which historians "are valued mainly as the suppliers of witness statements to biomedicine's 'progress', and hence, as allies in medicine's project of medical humanism." 6 These humanities-based explorations have a value all their own.

Arguing that the point of the academic medical and health humanities is in an important sense indistinguishable from that of any other form of scholarship may relax the impossible standards to which the field is commonly held by critics and proponents alike. But of course there is giving and taking, and leveling the playing field between disciplinary health and medicine studies-and the interdisciplinary medical and health humanities - subjects the latter to much of the same criticism so commonly bandied at the humanities in general: what, the skeptic asks, is its practical value?

\footnotetext{
${ }^{4}$ See, e.g., Bashford and Strange $(2007)$.

${ }^{5}$ Lowenthal (1985).

${ }^{6}$ Cooter (2011, quotation on p. 293).
} 
I will not canvass the myriad critiques of the question itself, nor the plethora of excellent responses that have been so ably supplied. I nevertheless wish to entertain the challenge seriously, because the studia humanitatis essentially revolved around the idea that education should be made practical. The educational program developed at least in part as a response to the endless disputations of the Scholastics, from whom we derive the term "cloistered" to describe the academic removed from understanding of and acquaintance with the daily lives of non-scholars. ${ }^{7}$ Humanist training was intended to equip students with the tools needed to influence politics, diplomacy, and law-in short, to impact the world in which they moved. The studia humanitatis were an educational movement founded on the hope of putting erudition to practical use, even while one can hardly read Petrarch, Montaigne, or Erasmus and find them guilty of treating the bounty of antiquity as a mere means to an end. The humanists, as I have noted, were early translational researchers.

But a tension obviously exists: the medical and health humanities are to be regarded as members of the kingdom of ends, and yet at the same time must strive for practical impact to be consistent with the educational legacy bequeathed by its ancestors. How? On what terms? On whose terms? And, of course, who gets to decide? These are difficult questions that, for this adept at least, admit of no easy answers. Indeed, I have spent the better part of the last decade essaying different approaches to these and related issues, although, like Sisyphus, I suspect that the answer lies within the process of pushing the boulder up the mountain-even knowing that it may come crashing down again.

In contemplating the scaling of peaks, scholarly or otherwise, I am reminded of Petrarch's paradigmatic Ascent of Mount Ventoux. As intellectual, moral, and spiritual sustenance for the climb, Petrarch tells us that he carried a copy of Augustine's Confessions, which represents a quintessentially humanist integration of erudition and learning in the service of practical aims. For why did Petrarch spend a day and a morning climbing the mountain? For the view, of course: "to see what so great an elevation had to offer."

Ad fontes!

\section{References}

Bashford, Alison, and Carolyn Strange

2007 Thinking Historically About Public Health. Medical Humanities 33(2): 87-92.

Charon, Rita

2001 Narrative Medicine: A Model for Empathy, Reflection, Profession, and Trust. Journal of the American Medical Association 286(15): 1897-1902.

Cooter, Roger

2011 Re-Presenting the Future of Medicine's Past: Towards a Politics of Survival. Medical History 55(3): 289-294.

Lowenthal, David

1985 The Past is a Foreign Country. Cambridge: Cambridge University Press.

Nauert, Charles G.

2006 Humanism and the Culture of Renaissance Europe. 2nd Edition. Cambridge: Cambridge University Press.

$\overline{7}$ There are multiple excellent sources for this, but one could do worse than to start with Nauert (2006). 
Repko, Allen F.

2012 Interdisciplinary Research: Progress and Theory. 2dnd Edition. Thousand Oaks, CA: Sage Publications Inc..

Robert, Frodeman, and Julie Thompson, Klein, and Carl, Mitcham, eds.

2010 The Oxford Handbook of Interdisciplinarity. New York: Oxford University Press

Tanya, Augsburg, and Stuart, Henry, eds.

2009 The Politics of Interdisciplinary Studies. Jefferson, NC: McFarland \& Company, Inc. 